\title{
Lung Function Test in Asthmatics Patients in UBTH: Medical Awareness and Anaesthetic Implications
}

\author{
Egbagbe E. E* and Adudu P. O**
}

\begin{abstract}
This report describes the result of a study on lung function tests on 75 asthmatics seen within a 6-month period (January 1 to June 30, 2004) at the University of Benin Teaching Hospital (UBTH), Benin City, Nigeria. There was a preponderance of females (60\%) to males (40\%); The result also showed that a large proportion of the patients had mild to moderate asthma (72 percent) while 28 percent of the asthmatics had severe asthma. The $\mathrm{FEV}_{1}$ was less than $60 \%$ in $28 \%$ of respondents. Four patients (5.3\%) had previous surgery with no adverse preoperative events.
\end{abstract}

No attempt was made to determine the exact prevalence of the condition but there seemed little doubt that asthma prevalence in Nigeria has increased markedly in the past 10 years. It therefore became necessary to create awareness about the usefulness of lung function tests. The medical and anaesthetic implications of the pattern of severity of the disease are discussed.

\section{INTRODUCTION}

Asthma is a reversible airway obstruction that is characterized by hyper-irritability and inflammation of the airways and wide variation over short periods of time, in resistance to flow in intrapulmonary airways $^{1}$. It is manifested clinically by

KEYWORDS: Words: Asthma, lung function tests, spirometer, peak flow meter, FEV ${ }_{1}, F V C$, Anaesthetic implication, Nigeria.

${ }^{*}$ Department of Medicine and **Department. of Anaesthesia, University of Benin, Benin City

Correspondence: paroxysms of dyspnoea, cough, wheezing and tightness of chest and it affects 0.1 to 10 percent of the African population ${ }^{24}$.

Lung function tests are simple, easy tests of pulmonary function, which are useful in distinguishing obstructive airway diseases from restrictive airway diseases. They suggest the severity of functional impairment and its reversibility with treatment using inhaled beta ${ }_{2}$ agonists and perhaps corticosteroids. Lung function tests have long been used as a clinical tool by physicians but not among the asthmatics in this region. Many deaths and unnecessary morbidity are connected with underuse of objective measurement of severity, underuse of inhaled 
and oral corticosteroids and inadequate supervision. Studies have shown that asthma outcome is improved if there is interactive management, that is involving patient and doctor $^{5}$. It is known that 5 to 10 percent of patients undergoing surgery are asthmatics and need anaesthesia. It was not clear in our centre if asthmatics were aware of available tests to assess the severity of their illness and the need to come to hospital to see the physician for treatment before the critical stage.

The essence of the study was to assess the degree of lung impairment and severity of disease and to create awareness about their usefulness among asthmatics including education on how to perform them.

\section{MATERIALS AND METHODS}

A total of seventy five stable asthmatics aged between 20 and 75 years and seen between January and June 30, 2004 were recruited after appropriate ethical approval.

The inclusion criteria included documented history of bronchial asthma, Peak expiratory measurements of at least $80 \%$ of the predicted value. Others were treatment with $\beta_{2}$ agonist only, demonstration of the ability to comply with the appropriate use of peak flow meter.

The exclusion criteria werePatients with unascertained diagnosis of bronchial asthma, Those on regular long term preventive medications, for example oral or inhaled steroids, mast cell stabilizers, theophylline, leukotriene modifiers and long acting beta agonist. Others were Current and ex-smokers. Those in whom clinical evaluation revealed a suspicion of the presence of chronic obstructive airway disease (COAD) or other significant respiratory disease and Suspected pregnancy.
Modified MRC Respiratory Procedure Questionnaire was interviewer administered. Questions were also asked on previous knowledge about lung function tests; their usefulness and if they owned or used miniWright Peak Flow meter. They were also asked about previous surgery or preoperative events.

Age of the patient (as at last birthday) was recorded. Procedure for the lung function test and snider's tests was explained and demonstrated to the patient; this was done to enable the patient understand and master the technique.

A portable peak flow meter was used to measure the peak expiratory flow rate of the patients in litres per minute $(\mathrm{L} / \mathrm{min})$. A portable simple spirometer was used to measure the forced expiratory volume in one second $\left(\mathrm{FEV}_{1}\right)$ and forced vital capacity (FVC). The FEV, and FVC were carried out according to the method of Brain, Kinght and Siddiqui. ${ }^{6}$

For the expiratory flow rate measurement, the patient was instructed to inhale maximally, then to exhale quickly and forcefully into the peak flow meter. The highest of the three trials was recorded in litres per minute (L/min).

The spirometer manoeuvres were performed on three occasions and the highest of the three values was recorded in litres ${ }^{7}$.

Prediction equations given by Patrick J. N., Femi Pearse DR ${ }^{8}$. was used to calculate the percentage of predicted value for each patient. For the Snider's match test, (bedside test) a lit match stick is held at 6 inches away from the patient who blows it out without pursing the lip. The test measures the forced vital capacity ${ }^{9}$. 
68 Journal of Medicine and Biomedical Research

Table 1: Age and Sex Distribution of Asthma Patients

\begin{tabular}{|l|l|l|l|l|}
\hline Age in Years & Male (\%) & Female (5) & Total & \% \\
\hline $20-25$ & $9(12 \%)$ & $12(16)$ & 21 & 28. \\
$25-35$ & $12(16)$ & $3(4)$ & 15 & 20. \\
$35-45$ & $3(4)$ & $12(16)$ & 15 & 20 \\
$45-55$ & $3(4)$ & $3(4)$ & 6 & 8 \\
$55-65$ & $3(4)$ & $12(16)$ & 15 & 20 \\
$65-75$ & - & $3(4)$ & 3 & 4 \\
TOTAL & $30(40)$ & $45(60)$ & 75 & 10 \\
\hline
\end{tabular}

Mean Age $=39.1 \quad \Sigma=15.13$

Table 2: Pattern of FEV1/ FEV1/ FVC ratio in Asthmatic Patients.

\begin{tabular}{|l|l|l|l|}
\hline$\%$ & $\begin{array}{l}\text { FEV1 in seconds, as } \\
\text { \% of predicted value } \\
\mathbf{( \% )}\end{array}$ & FEV1/ FVC ratio (\%) & Total (\%) \\
\hline $50-60$ & $21(28)$ & $27(36)$ & 48 \\
\hline $61-80$ & $33(24)$ & $21(28)$ & 39 \\
\hline $81-120$ & $36(48)$ & $27(36)$ & 63 \\
\hline Total & $75(100)$ & $75(100)$ & 150 \\
\hline
\end{tabular}

\section{RESULTS}

Majority of the asthmatics (28\%) were in the 2025 years age group and with a mean age of $39.1 \pm 15$ 13years. (Table 1). There was a preponderance of females $(60 \%)$ to males $(40 \%)$ in this study.
Forty two patients (56\%) showed below normal values for the $\mathrm{FEV}_{1} / \mathrm{FVC}$ ratio. Twenty one patients (28\%) had less than $60 \%$ of the predicted $\mathrm{FEV}_{1}$ value (Table 2). Forty two patients (56\%) had peak expiratory flow rate (PEFR) values below 300 litre/min while thirty three (44\%) had values above 300 litre/min (Table 3). 
Table 3: Peak Flow Rate in asthmatic Patients

\begin{tabular}{|l|l|l|l|l|}
\hline $\begin{array}{l}\text { Peak flow rate in } \\
\text { L/ min }\end{array}$ & $\begin{array}{l}\text { Males } \\
\mathbf{( \% )}\end{array}$ & $\begin{array}{l}\text { Females } \\
\mathbf{( \% )}\end{array}$ & Total & \% \\
\hline $150-200$ & - & $24(32)$ & 24 & 32 \\
\hline $201-299$ & - & $12(16)$ & 12 & 16 \\
\cline { 2 - 5 } & - & $6(8)$ & 6 & 8 \\
\hline \multirow{2}{*}{$300-400$} & $6(8)$ & $3(4)$ & 9 & 12 \\
\cline { 2 - 5 } & $9(12)$ & - & 9 & 12 \\
\hline \multirow{2}{*}{$401-500$} & - & - & - & - \\
\cline { 2 - 5 } & $3(4)$ & - & 9 & 12 \\
\hline $501-650$ & $9(12)$ & - & 3 & 4 \\
\cline { 2 - 5 } & - & - & 75 & 100 \\
\cline { 2 - 5 } & 3940 & - & & - \\
\hline \multirow{2}{*}{ Total } & 30 & 45 & & 3 \\
\hline
\end{tabular}

Table 4:Snider's Match Test Results in Asthmatic Patients

\begin{tabular}{|l|l|l|l|}
\hline Sex of Patients & $\begin{array}{l}\text { Able to blow out } \\
\text { lit match (5) }\end{array}$ & $\begin{array}{l}\text { Unable to blow out } \\
\text { lit match (5) }\end{array}$ & Total (\%) \\
\hline Male & $21(28)$ & $9(12)$ & $30(40)$ \\
\hline $\begin{array}{l}\text { Female } \\
\text { Total }\end{array}$ & $15(20)$ & $30(4)$ & $45(60)$ \\
\cline { 2 - 4 } & $36(48 \%)$ & $39(52 \%)$ & $75(100)$ \\
\hline
\end{tabular}

Table 4 showed that $52 \%$ of the patients had abnormal result and this represented the forced vital capacity (FVC) by the bedside of the patients with abnormal results, $40 \%$ were females.

\section{DISCUSSION}

The definition of asthma has long been a subject of controversy in the medical literature. The latest definition of asthma puts it as "a clinical syndrome characterized by increased hyper-responsiveness of the tracheobronchial tree to a variety of stimuli". The usual method for diagnosis of asthma in most parts of Nigeria has been exclusively based on medical history and physical examination. However, majority of the asthmatics perceive their disease poorly when compared with pulmonary function. Pulmonary function tests however provide an objective assessment of the severity of airway obstruction and help to develop an algorithm upon which treatment protocol can be developed. 
Two measurements which are the forced expiratory volume in one second $\left(\mathrm{FEV}_{1}\right)$ and the peak expiratory flow rate (PEFR) are particularly useful in monitoring patient with asthma. These two tests provide objective, quantifiable measures of lung function. Not only are these tests useful in monitoring patients, they are also useful in monitoring the effects of exposures, in assessing the risks of surgery, and in evaluations performed before employment or for insurance purposes. These two lung function parameters are reduced during acute asthmatic attacks but the mild asthmatics may have normal values in between attacks. One of the characteristics of asthma is the variation in airflow obstruction. Considerable reduction in the PEFR or FEV over short periods can be recorded by serial measurement using the spirometer or home measurement of the PEFR twice daily ${ }^{10}$. The parameter $\mathrm{FEV}_{1} / \mathrm{FVC}$ will be reduced in obstructive diseases such as asthma but normal or elevated in restrictive airway diseases ${ }^{11}$. In this study amongst Nigerian asthmatics, $28 \%$ of patients had values less than 60 percent of predicted. These patients can be classified as having moderate to severe asthma. The study also showed that $64 \%$ of the patients had an $\mathrm{FEV}_{1}$ ratio equal to or lower than $75 \%$ and $56 \%$ had PEFR lower than $300 \mathrm{~L} / \mathrm{min}$.

Prevalence rate of surgical conditions in asthmatic patients is high $^{12}$ and the anaesthetic implications of this disease are therefore important. It should be recognized that acute severe asthma is associated with hypoxaemia, dehydration, acidemia and hypokalaemia. This makes such patients with acute severe asthma vulnerable to cardiac dysrrythmias and cardiopulmonary arrest $^{13}$.

Treatment of asthma include the use of ${ }_{2}$ adrenergic drugs, parasympatholytic agents and systemic or inhaled corticosteroids. The current use of steroids early in the course of asthma ${ }^{14}$ means that many of the asthmatic patients would need steroid premedication to prevent adrenal suppression if used within six weeks of surgery.

The main purpose of preoperative lung function tests is to identify patients at risk of preoperative respiratory complications the asthmatics have a fourfold increase in preoperative respiratory complications $)^{15}$ and to institute appropriate perioperative therapy. Preoperative assessment of lung function also establishes baseline function and the feasibility of surgical intervention. CONCLUSION

Despite the battery of tests available to characterize bronchial asthma, the simple forced expiratory spirogram remains the most reliable technique to diagnose asthma and gauge its severity. A well performed forced expiratory spirogram also remains the cornerstone of pulmonary functions testing.

The test should be made mandatory in every chest clinic and doctors must insist that patients have a regular measurement of their lung function using peak flow meter at home and spirometer/peak flow meter in the clinic.

The study will be followed by a larger one to determine the long-term outcome of this conscious effort to improve awareness about the use of lung function tests. A case is made for education of new asthmatics on the use of lung function tests for earlier intervention by doctors.

\section{References}

1. Scadding JG. Definition and clinical categories of asthma. In Asthma, 2nd Edition (eds Clark TJH, Godfrey S), Chapter 1, Chapman \& Hall, London.

2. Godfrey RC. Asthma and Ige levels in rural and urban communities of the Gambia;Clinical Allergy 1975; 5:201-207. 
3. Keely DJ, Jerill P, Gallivan S. Comparison of the prevalence of reversible airways obstruction in rural and urban Zimbabwean. Thorax $1991 ; 46,549-555$.

4. Cookson JB and Makoni G. Prevalence of asthma in Rhodesian Africans. Thorax 1980; 35:833 837 .

5. Pedersen S. and Silverman $M$. Management of Asthma: a consensus statement. Arch Dis Child. 1989, 64: $1065-79$.

6. Black D, James WP I, Besser GM. Obesity. J Roy Coll Physicians Lond 1983; 17:5 65 .

7. Brain SR, Knight L, Siddiqui KA. Pulmonary function tests. In: Brain SR, Everrett ED, Perry MD (eds). Textbook of Pulmonary Medicine, New York, Elservier Sciences Publishing, 1989.

8. Patrick J. N., Femi Pearse D. Reference values for FEV1 and FVC in Nigerian men and women. A graphic summary. Nig. Med. Jour. 1976; 6:380 -384.

9. Rock P. Evaluation and perioperative management of the patient with respiratory disease. Anesthesiology Grand rounds 2002, 253:11-7.
10. Turner Marwick M. On observing patterns of airflow obstruction in chronic asthma. Br. J. Dis Chest 1977; $7: 73-74$

11 Morris JP, Temple Wp, Koski A. Normal values for the ratio of one second forced expiratory volume to forced vital capacity. Am Rev. Resp. Dis. 1973, 108.1000-1003.

12 Warner D. Perioperative respiratory complications in patients with asthma: Anaesthesiology. 1996, 85:455-66

13 Phipps P., and Garrard CS. The pulmonary physician in critical care: acute severe asthma in the intensive care unit. Thorax 2003, 58:81-88.

14 Bishop MJ.; New perspectives on the patient with reactive airways. IARS 1994, $14-18$.

15 Roizen MF. Anaesthetic implications of concurrent diseases. In: Anaesthesia. Cuchiara RF. Miller E D. (Jr.) Reeves GJ., Roizen MF. Savaraese JJ. Eds. Churchill Livingstones: New York, 4th edition, 1994; 1903 -1014. 